\title{
MULTIFUNCTIONAL AGRICULTURE: AN ENGINE OF REGIONAL ECONOMIC GROWTH?
}

\author{
Alan Randall \\ The Ohio State University, Columbus, OH 43210-1067, USA, randall.3@osu.edu
}

\begin{abstract}
The historical role of agriculture in economic geography and recent conceptual developments - including multifunctional agriculture (MFA), the new economic geography, amenity-driven growth, and the "world is flat" and "creative class" hypotheses - are examined, and recent empirical research in North America and Europe is reviewed, in order to assess the potential for MFA as an engine of regional economic growth.

Ideal MFA policy corrects market failures and is mostly amenity-augmenting. It has the capacity to enhance opportunities for farmers on urban fringe; stimulate growth in high-amenity rural regions accessible to cities that offer opportunities for high-value work; and generate growth in relatively remote high-amenity regions. The scope for market-failure-correcting MFA policy to propel economic growth in lessfavored regions is limited - remoteness is non-responsive to policy in the short to medium term, and amenities that attract in-migration (e.g. proximity to sea, lakes, mountains, pleasant climate) are givens for favored locations but can at best be complemented by pro-active policy but not trivial.

While this paper focuses on regional economic growth, it well to remember that growth is not everything. Regions unlikely to experience growth need to create satisfying futures. Market-failure-correcting MFA policy has the potential to improve quality of life, well-being, and perhaps incomes in many if not all rural places regardless of location. This accomplishment would not be trivial - economic growth for all regions regardless of resources, amenities, and remoteness is not a serious prospect, and regions in decline face daunting problems maintaining essential services and quality of life.
\end{abstract}

Key words: Multifunctional agriculture, regional economic development, agglomeration, amenity driven growth, peri-urban areas, fiscal transfers

\section{Introduction}

It might be conjectured that new models of regional economic development, combined with the emerging understanding of multifunctional agriculture, would suggest a new and perhaps more optimistic perspective on the potential of agriculture as an engine of regional economic growth. My purpose here is begin the process of surveying the relevant literature, unraveling the arguments and gleaning evidence from the published empirical record, and drawingout some implications that may help focus our deliberations over the next few days.

Historically, it has been difficult to make the case for agriculture as an engine of economic development in rural regions. The broad sweep of the evidence has tended to point in the opposite direction - the rising value of labor in the industrial and post-industrial economy has tended to draw workers to urban centers, and in so doing depopulate rural regions. To the extent that the rural population has proven relatively immobile, spatial inequalities in income, wealth, and opportunity have persisted to the detriment of rural regions. The traditional rural development agenda has had perhaps three organizing objectives: to correct any market failures that would disadvantage rural regions disproportionately; to identify niches where rural communities can compete in the industrial and post-industrial economies, and to find ways of providing adequate services (especially, but not limited to, health, education, and communications) to support a desirable quality of life in rural regions.

Europe has its own particular perspective on regional and territorial economic disparities, arising from a legacy of unequal participation in the industrial revolution, the partition of Europe into adversarial blocs in the cold war years, and the commitment of the European Union to economic development in economically lagging regions and economic integration throughout the EU. More recently, successive waves of EU expansion have magnified the task of economic integration.

The question motivating this paper is whether new models of regional economic development (e.g. the "new economic geography"), new insights that have captured a lot of popular attention in recent years (e.g. amenity-driven growth, the "earth is flat", and the "rise of the creative class"), and new perspectives on agriculture as a source of amenities (multifunctional agriculture, MFA) that might attract worker/consumers and hence growth are sufficient to fundamentally change our perspective on rural development 
and economic integration, and change it in a more optimistic direction. To what extent does the contemporary emphasis on MFA, as opposed to commodity production agriculture improve prospects for regional economic development and make agriculture more central to those prospects?

\section{Building blocks}

To set the scene for subsequent developments, I begin with a brief review of the economic role of commodity agriculture, and the concepts of economic geography based on the work of J. H. von Thunen.

Agriculture, understood as production of food and fiber commodities, allowed enormous expansion of carrying capacity for humans and generated huge rents - the cathedrals and palaces of Europe are a tribute to the ability of agriculture to generate massive surpluses in pre-industrial times. The modernization of agriculture in the eighteenth and nineteenth centuries released most of the agricultural labor force, paving the way in that respect for the industrial revolution. Labor simply matters very much less than it used to, in the production of food and fiber commodities. Land and natural resources also matter less, for two reasons: agricultural technologies have been land-saving as well as labor-saving; and the colonization of the "new world" vastly expanded the land base and the supply of food and fiber commodities. For more than a century now, new-world exporting nations have tolerated a depopulation of the countryside even greater than Europe's, and they tend to believe that the relatively large proportion of the labor force in agriculture in Europe today can be explained only by maintained impediments to food and fiber imports.

The pioneering economic geography of Thunen assumes a city serving an essential function (marketing, perhaps), and organizes economic activity around the city on the basis of a single but very fruitful insight - distance is costly, and it costs more for some activities than others. The city is located, one presumes, by some initial but unexplained advantage, and the surrounding countryside is homogenous except for the matter of distance from the city. The wilderness (land abandoned to economic activity because it is impossible to generate positive rents by working it) is not infertile badlands; rather, it is just too distant given prevailing prices and technology - an assumption that allows it to serve as a reserve to be brought into production should economic conditions warrant it. An additional purpose served by the wilderness is to isolate the city-state from economic competition from other city-states.

Thunen's economic geography leads logically, I think, to core-periphery models of the regional economy. Urban theorists applied Thunen's insights to the internal economic geography of the city which, in their models, was characterized by lower land prices and increasing lot size with increasing distance from the central business district. The city grows to absorb farmland by out-bidding farmers at the urban fringe, and distance from the city determines the use and value of agricultural land. Basic core-periphery models do not offer much hope for economic development in the periphery - it is the city that provides the economic engine for the region, while the hinterlands provide raw materials and undifferentiated labor that can be bid away by the core.

\section{The "new economic geography"}

The new economic geography, NEG (Krugman 1991) was motivated by the desire to explain a much richer pattern of agglomeration that seems to persist in the real world. With roots in Krugman's earlier contributions to the international trade literature, it locates population concentrations on the basis of some initial advantage in production, and explains their relative growth mostly by agglomeration efficiencies and, in the case of sophisticated products, a deepening labor market. NEG's organizing objectives (Fujita and Krugman 2002) are to explain the economics of location in terms of the whole economy, which argues for general equilibrium formulations with explicit micro-foundations; and to identify centripetal and centrifugal forces (forces of attraction and repulsion) that explain agglomeration and its limits. Monopolistic competition and increasing returns play important roles in NEG, along with costs of transportation between regions.

In the simplest models, the manufacturing (i.e. urban) sector produces a continuum of varieties of a horizontally differentiated product; each variety is produced by a separate firm with scale economies, using workers as the only input. The agriculture sector produces a homogeneous good under constant returns, using farmers as the only input. More complex models allow vertical and horizontal differentiation of products and heterogeneity of urban workers, and a picture emerges of highly agglomerated cities as having deeper labor markets, i.e. greater horizontal and vertical differentiation among workers, including more highly skilled and specialized workers. NEG is open to the idea that concentrations of diversified skilled workers (human capital) may attract firms to a region, especially specialized firms.

Eventually, the idea of agglomeration (from NEG) was added to the core-periphery models (rooted in Thunen) of the city and surrounding hinterland - increasing complexity of the urban economy (as well as increasing size) was an advantage, because it generated cost advantages in production.

Frankly, incorporation of urban agglomeration into coreperiphery models does little to improve the prospects for economic development in the more remote parts of the periphery. Agricultural rents may rise with growth of the city (especially for land near the urban fringe). Beyond the fringe, Thunen-based models permit increasing labor intensity as land rents rise, but the labor-saving nature of technological progress in agriculture tends to militate against it.

From the perspective of modern core-periphery models, can commodity agriculture serve as an engine of regional 
economic growth going forward? Perhaps it can, in a few favored places, but it seems very unlikely to do so across the board. After all, commodity agriculture is peripheral (literally and metaphorically) in a theory of regional growth that emphasizes agglomeration efficiencies and deepening labor markets. Not only that, but there is some empirical evidence for the "resources curse" hypothesis. Gylfason (2000) presents cross-sectional evidence that natural resource abundance and extensive agriculture appear to have impeded economic growth in the transition economies in Central and Eastern Europe and Central Asia since 1990. Possible explanations are that heavy dependence on natural resources and agriculture may result in rent seeking (e.g. corruption) and policy failures (e.g. inflation), and may induce a complacency that discourages genuine saving, thereby retarding economic growth.

\section{Amenity-driven growth}

The new economic geography paid no attention to household preferences and hence locational amenities. But national wage-rent hedonic models, beginning with Blomquist et al. (1988), have indicated consistently that highamenity regions have an advantage in attracting workers and consumers. Specifically, they document that at the margin worker-consumers will accept wage discounts in order to move to (or remain in) high amenity regions, and demand wage premiums to work in low amenity regions.

Conceptual models show that, under certain conditions, high-amenity regions may attract residents and thereby experience growth (Irwin et al. 2008). Three factors help rural regions (rural amenities, urban disamenities, and urban congestion), and one hurts (urban efficiencies from agglomeration). To begin sorting-out the impacts of these various influences in a systematic way, Irwin et al. adapted a simple two-region dynamic model of regional factor mobility and urban agglomeration (Fujita and Thisse 2002) to examine the role of environmental amenities and urban congestion in core-periphery patterns of regional development. People are mobile between the two regions but they must live where they work, so their location decisions are influenced by the wages and amenity levels prevailing in each region.

In principle, the core-periphery pattern may emerge from some initial advantage in resources or amenities plus agglomeration effects, so an amenity-driven core-periphery pattern is possible. However, as is common in this kind of modeling, assume that an urban core has arisen due to some historical resource advantage and subsequent agglomeration effects. With growth in the urban core, urban disamenities (congestion, pollution, etc.) may eventually outweigh the production externalities and urban amenities that drove urban growth, dispersing population and economic activity to the periphery region. This outcome is not guaranteed, but depends on the relative amenity endowments of the two regions. For high amenity periphery regions, the model predicts an irreversible change in population location so that growth concentrates not in the core but in the periphery. On the other hand, periphery regions with moderate amenity endowments may gain some population and production, but will never develop into new core regions. Those regions with amenities below a certain value will fail to gain population, despite the core's degradation. Thus, rural regions may benefit from congestion and pollution in urban regions, but only if they have a sufficient "pull" of their own.

There is some scope for pro-active public policy to promote amenity-driven rural growth. Local government investment in amenities in the periphery region can attract population and production to the periphery, but only if the initial amenity endowment is relatively high and the utility gain from augmenting amenities exceeds the utility loss from additional taxation.

In support of the possibility of amenity-driven growth, I have invoked empirical evidence that wage premiums and discounts are associated respectively with low-amenity and high-amenity regions, and modeling results that identify conditions under which urban disamenities and rural amenities might eventually overcome urban production externalities, thereby reversing the pattern of urban growth and rural depopulation. In addition, there is some empirical evidence for amenity-driven growth. Rappaport and Sachs (2003) have shown not only that coastal counties in the US have experienced disproportionate economic growth over the last 80 or 90 years, but that their economic advantage has shifted in that time, with advantages in market access (e.g. seaports) becoming less important and advantages in amenities more important.

There seems little doubt that amenities matter to growth prospects and are becoming, if anything, more important. However, the potential for effective amenity-oriented growth strategies and policies is much less clear, given that much of what counts as locational amenities (mountains, lakes, the sea-coast, pleasant climate) in Blomquist et al. and Rappaport and Sachs are, from the local perspective, givens rather than variables responsive to policy.

\section{Multifunctional Agriculture}

Agriculture produces a broad array of valuable amenities in addition to commodity outputs. The concept of multifunctional agriculture (MFA) is intended to capture the valuable products, beyond food and fiber commodities, that come from agriculture (Nilsson et al. 2008). If commodity outputs alone were at stake, economists would argue, free markets would ensure their efficient production and pricing. The MFA concept has economic cogency when noncommodity outputs are valued but would be un priced (or systematically under priced), and therefore under produced, in a free-market world. The economic argument for taking MFA seriously is a market-failure argument (Romstad 2004) - free markets fail to value non-commodity outputs fully, and thus to provide incentives for their optimal production implying a role for public policy to correct the market failure.

The market failure justification for MFA policy argues for treating place-based regional economic development policies 
as distinct from MFA, because they are not so readily justified by appeal to market failure. Therefore, I distinguish value-added agriculture and amenity-augmenting policies (which I will call MFA) from place-based economic development policies, because they have quite different rationales and, plausibly, different impacts on prospects for regional economic growth. ${ }^{1}$ Thus, I am defining MFA outputs to include control of nonpoint pollution and other negative externalities from farming; food and fiber products that are artisanal, produced by traditional methods and/or in historic facilities, regionally-branded, etc, and in some (but not all) cases marketed locally and/or directly; agritourism; production on farms of amenities (differentiated scenic amenities) and public goods (water catchments, carbon sequestration), and landscape-level amenities associated with agriculture and rural life (scenic, culture-landscape). MFA policies and programs are those intended to encourage and reward MFA outputs. In contrast, place-based economic development policies in the EU include rural development measures under Pillar II, infrastructure programs and projects supported by the European Regional Development Fund, and fiscal transfers to low-income regions.

Both kinds of objectives are in fact supported by targeted agricultural policies in the United States and the European Union (Cochrane and Wojan 2008). Furthermore, in both the US and the EU, traditional agricultural commodity programs also support MFA objectives (it is claimed), to the extent that they are defended as supporting rural communities and traditional values associated with farming (typically, the family farm in the US, and cultural landscape in Europe). ${ }^{2}$ This section is focused on amenity-augmenting (MFA) policies, but place-based economic development policies are discussed in a later section.

Amenity-augmenting policies and programs for agriculture and rural regions expand the concept of agriculture to include production of various kinds of amenities. In contrast to commoditization, artisanal, regionally-branded, etc. food and fiber products are included in MFA, as are amenities associated with agriculture; and these approaches introduce prospects for enterprise diversification, improved viability of peri-urban farms, and perhaps improved regional economic viability (Clark 2009, and Clark et al. 2007).

However, it is important to recognize that there are perhaps major differences among regions in their potential to benefit from efficient MFA policies and programs. Regions vary in their potential for efficient amenity production, with regions high in natural amenities having clear advantages. Regions differ also in their remoteness from population centers. Remoteness always imposes costs, but there are differences among MFA products in the costs of remoteness - amenities that are consumed on-site are more disadvantaged by remoteness than differentiated products that can be transported readily. Randall $(2002,2007)$ has argued that differences in remoteness imply perhaps substantial regional differences in efficient green prices, more so for amenities consumed on-site.

\section{Conjectures from the semi-popular literature}

The "world is flat" hypothesis. The journalist Thomas Friedman has attracted much attention with his "the world is flat" hypothesis (2005). Basically, he has argued that the inexpensive transmission of information allows effective economic competition from remote regions, an argument he presents in broad generalizations supported by anecdotal evidence. One imagines a lone individual in a remote village with a laptop computer recharged by a portable generator, possibly itself animal or human-powered, competing effectively in the global market for one or another kind of intellectual product. And perhaps so - there may be a sprinkling of such cases. But for regional economic development, we would need to imagine large informationbased enterprises emerging in remote places with surplus labor, and competing effectively in global markets.

It can be argued that this hypothesis is plausible for work that is readily commoditized. However, most high-value work is not readily commoditized - Leamer (2007) proposes the following hierarchy from more to less commoditized: type this page; edit this page; write an article for an economics journal; write a good joke. For work that is not readily commoditized, it is reasonable to conjecture that agglomeration efficiencies, especially the deepening of the labor force, matter.

Post-industrial technology and "the rise of the creative class". Agglomeration efficiencies are unlikely to diminish in the post-industrial age, and post-industrial technology tends to widen the value gap between creative and commoditized work.

The "rise of the creative class" hypothesis (Florida 2002) suggests that cities can prosper by sustaining an urban environment attractive to creative workers. The creative class hypothesis adds to the deepening labor force argument by suggesting that creative workers choose locations with a high level of urban amenities. The hypothesis is that regional development now depends on novel combinations of knowledge and ideas, that certain occupations specialize in

\footnotetext{
1 confess that the distinction I am making between amenity-augmenting policy (MFA) and place-based economic development policy is inconsistent with both US and European linguistic norms. US officialdom avoids the term MFA (perhaps for reasons rooted in international trade concerns - see Randall 2003, 2007) but recognizes the policy-relevance of payments for ecosystem services, and programs to promote local, natural, and organic foods as well as more generic access to a safe and healthy food supply. The US has its framework of rural development programs, too, but views them as quite distinct from the above MFA-like programs. It seems that Europeans are more comfortable than I am, with including place-based regional economic development policies in their notion of MFA.

2 See also the Special Issue Comparing US and European Rural Development Policies, EuroChoices 7(1). 2008. http://www3.interscience.wiley.com/journal/ $119421781 /$ issue
} 
this task, that people in these occupations are drawn to areas providing a high quality of life, and thus the essential development strategy is to create an environment that attracts and retains these workers.

Attention tends to be focused on two distinct aspects of the creative class hypothesis, for quite different reasons. First, what defines the set of creative workers? The tendency is to focus on certain occupational and professional groups rather than, say, certain sectors of the economy, or the higherwage strata (as one might, if one were identifying high levels of human capital). This latter distinction matters, if the aim is to test the creative class hypothesis vis- $\alpha$-vis the less controversial claim that concentrations of high-humancapital workers tend to attract innovative firms to a region. Second, the distinction between the creative class hypothesis and the labor force deepening (i.e. high and extensively differentiated human capital) hypothesis acquires heightened significance in the context of America's "culture wars". A creative class sub-text that the gay community includes more than its share of creative workers, and therefore should be courted rather than repulsed by economically-ambitious cities, tapped into a contemporary US political controversy, as laws perceived as anti-gay were proposed and passed in some cities and states.

\section{Post-industrial technology, the "creative class" hypothesis, the "world is flat" hypothesis, and amenity-driven growth - empirical evidence}

Post-industrial technology is less dependent on in situ resources, value is provided less by bulky commodities and more by technologically sophisticated products and services, and information substitutes in considerable degree for transportation. So, intuition suggests that workers and their employers face lower cost-penalties for locating in remote regions. The "creative class" hypothesis, the "world is flat" hypothesis, and the amenity-driven growth hypothesis all depend on the idea that the grip of distance on economic prospects is loosening.

The creative class hypothesis. Empirical evidence re the "creative class" hypothesis is mixed and controversial (McGranahan and Wojan 2007, Boschma and Frisch 2007, Gabe et al. 2007, and Hoyman and Faricy 2009) - and much of the controversy surrounds the appropriateness of definitions and adequacy of measures of the creative class.

McGranahan and Wojan report a series of empirical studies of recent economic development performance in US rural and urban counties. Among their results, we find that creative class presence supports economic growth and is associated with high levels of natural amenities in rural counties. In urban counties there is a strong association between creative class presence and growth, although the association with natural amenities is not so strong. However, as the authors report, these results are sensitive to the definition of the creative class: "... the results depend on a recast creative class measure, which excludes from the original Florida measure many occupations with low creativity requirements and those involved primarily in economic reproduction. The measure conforms more closely to the concept of creative class and proves to be more highly associated with regional development than the original Florida measure."

Boschma and Fritsch test the creative class hypothesis with data on regional growth in Europe. They, too, define the creative class in terms of professions not industries. Findings include: the presence of the creative class is positively associated with regional economic growth; health care and education facilities have only modest association with presence of the creative class; and the regional share of the creative class among the labor force is positively associated with a climate of openness and tolerance - urbanization per se is not enough.

Hoyman and Faricy, and Gabe et al. are less inclined to endorse the creative class hypothesis. Hoyman and Faricy, analyzing data from 276 US metropolitan statistical areas, report that the presence of the creative class is not related to growth, whereas human capital predicts economic growth and development, and social capital predicts average wage but not job growth. Nevertheless, they found that clusters of universities correlated highly with economic growth. They do not shy from policy recommendations, warning against the use of "creative class" strategies for urban economic development. I suspect that different definitions of the creative class help explain the very different conclusions of Hoyman-Faricy, compared to McGranahan-Wojan and Boschma-Fritsch; and I am not sure what exactly it means to conclude that high human capital and clusters of universities help economic growth but the creative class does not.

One way or another, it seems that all three categories (high human capital, the talent attracted by clusters of universities, and the creative class) are associated with the deepening of the labor force, so the deepening hypothesis is not rejected. On the other hand, empirical correlation between deepened labor force and economic growth is not enough to establish that policies targeted to attracting highquality workers constitute an effective development strategy, or to determine what kinds of amenities are most effective at attracting the right kinds of workers.

"The world is flat" hypothesis - that information technology has lowered the costs of distance and hence the economic penalty for remoteness, dramatically expanding the set of effective competitors in global markets and equalizing the playing field - has intuitive appeal and some anecdotal support. Nevertheless, despite Friedman's hypothesis that distance matters less in the information age, the long-established empirical result that bilateral trade volume decreases with distance seems secure. Disdier and Head (2008) completed a meta analysis of 103 published studies, and concluded that the estimated negative impact of distance on trade increased around the middle of the twentieth century and has remained persistently high since then. Furthermore, at the regional level, empirical research 
on growth shows that distance still matters in Europe (Basile 2008) and North America, and its importance may be increasing over time (Partridge et al. 2009, 2008).

If anything, the work of Partridge and colleagues shows that proximity within the urban system plays a stronger role - stronger than other factors such as market potential and amenities, and growing stronger over time. Fast-growing small cities and rural regions tend to be accessible to large and/or fast-growing cities and, overall, the hinterlands' population appears to be redistributing itself to be nearer to, if not exactly in, larger urban centers. At the intra-regional level, there is evidence suggesting that information technology complements rather than substitutes for face-toface interaction. For example, Sohn et al. (2002) report that in the metropolitan Chicago region information technology has contributed more to concentration than to dispersion of the urban spatial structure.

How are we to reconcile agglomeration effects, which are large and apparently growing, with Friedman's premise that the costs of distance are decreasing? While it makes sense that agglomeration matters more to high-value work, it is not unimportant to work that seems readily commoditized. Furthermore, commoditization seems to be a matter of degree: while routine tasks in the manufacturing of clothing have been outsourced successfully to remote places with very low wages, the outsourcing of relatively mundane work in information processing has benefited entrepreneurs in the agglomerated cities of Bangalore and Hyderabad much more than independent contractors in remote regions.

Amenity-driven growth. As reported above (Section 4), anecdotal evidence and theoretical modeling support the possibility of amenity-driven growth, at least in favored locations. Partridge (2008) regards such cases as exceptions to the general rule (supported by his extensive empirical research) that proximity more than anything else drives growth and its influence is if anything increasing.

From an American perspective, this raises a conundrum. In the post-war period (more than 60 years, now), changes in the distribution of population and income have been rather dramatic, and the big continuing trends have been the increasing concentration of population in the coastal regions, the mountain west, and the south (Rappaport and Sachs, 2003). Coastal and mountain regions are considered highamenity ceteris paribus. The south enjoys more hours of sunshine than other regions, and electric air conditioning has reduced the cost of dealing with unpleasantly warm conditions whereas there have been no comparable advances in accommodating snow and ice in the north. So, a plausible story can be told of sweeping multi-generational trends in the distribution of the US population toward places and regions that enjoy amenity advantages.

During this long post-war period, several major cities in the south and the mountain west (e.g. Atlanta, Denver,
Phoenix, San Diego) have emerged as centers of thriving economic regions. Whatever the natural and amenity advantages of these sites, at some point agglomeration kicked-in, and the endogenous growth dynamic took over. ${ }^{3}$ Over the long haul, remoteness is endogenous - some remote places become central and some places that used to be central are at risk of becoming remote. Suffice it to say that our understanding of the influence of amenities on economic growth seems incomplete. Perhaps there are some timeinconsistencies in the evidence and/or our interpretation thereof.

An intuitively appealing generalization is that distance, or conversely proximity, always matters to growth prospects whereas natural amenities may provide opportunities for favored places and regions, and cities that strive to maintain a high level of urban amenities may be rewarded.

Because agglomeration matters less for consumers (e.g. the internet is an efficient provider of a broad suite of consumer amenities) than for firms, it can be argued that amenity-seeking consumers will be less disadvantaged by remoteness. Such consumers will include some who can use information technology to work remotely, but perhaps even more whose income is independent of their labor contribution. Intuition suggests that retirees are likely to be over-represented among footloose amenity-seeking consumers, and some favored communities will be able to prosper by attracting more than their share of economicallyindependent retirees. But, again, evidence is mostly anecdotal rather than empirical and systematic.

\section{Persistent spatial inequalities and place-based policies}

Income differences may exaggerate the magnitude of spatial inequalities in economic well-being - lower housing costs, lower taxes, and higher amenity levels are just three of the things that would raise "full income" for some households in relatively remote regions. Nevertheless, spatial inequalities are real and more persistent than standard economic theory would predict. Place-based economic development policies are often invoked to address persistent spatial inequalities.

While the political system (itself place-based electorates are defined spatially) continues to support them, the consensus among economists In the US is that placebased economic development policies are mostly ineffective. The World Bank (2009) takes a similar position on a global scale - place-based policies are wasteful and run counter to spatial efficiency.

In the European Union, place-based policies enjoy political support (European Commission 2006), and the EU maintains a considerable slate of rural development policies

\footnotetext{
3 Krugman (1993), addressed the flip-side of this question - how can Chicago's regional pre-eminence be explained, when it seems to have enjoyed few natural advantages? Using a general equilibrium model he concludes that, while concentration could have occurred at any of several sites, once it occurs the endogenous growth dynamic is self-reinforcing.
} 
and programs (Cochrane and Wojan 2008). There is a diversity of views among economists as to the justification and effectiveness of these policies (Bureau 2008, Winter 2008).

Some empirical evidence can be brought to bear, regarding the impacts of these policies and programs. Interregional fiscal transfers have long been used in the EU to encourage economic integration of lagging regions. Checherita, et al. (2009) examined evidence on the role of net fiscal transfers to households and EU structural funds for per-capita output convergence across a large sample of European regions during the period 1995-2005. They found that net fiscal transfers, while achieving regional redistribution, seem to impede output growth and promote an "immiserising convergence": output growth rates in poor receiving regions decline by less than in rich paying regions. EU structural and cohesion funds spent during 1994-1999 had a positive, but slight, impact on future economic growth, mainly through the human development component. Their summary finding is that the major place-based economic development policies in the EU have reduced regional income disparities but not disparities in output per capita.

Given that EU economic integration facilitates trade and encourages foreign direct investment (FDI) flows among member countries, Borota and Kutan (2008) investigated the impact of the trade and FDI variables on the growth performance of the EU-15 group. They report no evidence that trade and FDI have reduced disparities in capital formation. However, there is evidence that net FDI inflow has accelerated technology transfer, suggesting that FDI has served mostly as a special channel for technological transfers. While regional disparities in capital formation within the EU persist, to the extent that the EU integration has caused higher FDI inflows in lagging regions, it is clear that this process had a beneficial impact on growth via technology transfer.

These recent studies can be interpreted as providing only weak support for place-based economic development policies in the EU. Transfers raise incomes in lagging regions, but lower incomes by a greater amount in net-payer regions; in lagging regions, fiscal transfers have raised incomes but not output; and foreign direct investment in lagging regions has not reduced disparities in capital formation, but it has served as a vehicle for technology transfer.

\section{Conclusions}

The above review supports some broad-brush conclusions about multifunctional agriculture and economic development in rural regions. I begin with two stylized facts and draw-out some of their implications, and then conclude with some implications for the potential contribution of multifunctional agriculture to regional economic development.
Stylized fact 1: Ideal MFA policy is mostly about correcting market failures, and is desirable for all the usual economic reasons (Randall 2002, Romstad 2004). MFA policy has the potential to internalize the negative externalities from agriculture, and to provide and/or enhance open space, wildlife habitat, environmental amenities, recreation and tourism, differentiated food and fiber products (e.g. locally produced, "natural", and organic), food safety and security, production using traditional methods and historical buildings and equipment, and cultural landscape. To the extent that it actually corrects market failures, MFA policy will improve quality of life, well-being, and perhaps incomes in many if not all rural places (farms and villages), regardless of location.

Stylized fact 2: Distance still matters, and conversely remoteness remains an impediment to growth (Partridge et al. 2008, 2009). Thus far, the evidence fails to support claims that the "creative class" and "world is flat" hypotheses offer systematic antidotes to the tyranny of distance. ${ }^{4}$ Amenitydriven growth is possible but does not offer a general panacea. High levels of natural amenities, and/or educational and cultural amenities may bring prosperity to some favored places. There are many examples of smaller US cities that seem to be thriving because of environmental amenities (Coeur d'Alene ID, and Sarasota FL), high levels of educational and cultural amenities (Charlottesville VA), or both (Missoula MT). However, it is not clear that college towns and places with natural amenities have in general excelled in economic growth.

It follows directly from the tyranny of distance that, for regions seeking sustainable prosperity, there are few quick fixes. Given that remoteness is exogenous in the short to medium run, the most promising strategies seek to generate a regional advantage in performance of high-value work, and involve long-term, sustained focus on education, infrastructure, quality of life, and favorable economic and fiscal policies.

Now we consider some implications for the potential contribution of multifunctional agriculture to regional economic development.

MFA and regional development objectives (1). Consider ideal MFA policy as addressed to correcting market failures, and assume MFA increases amenities in rural areas. What regional growth response can we expect? It seems the growth response will vary by region and locality, and will depend on amenity level and remoteness:

- MFA will enhance opportunities for farmers on the urban fringe. In the US, Clark (2009) has documented a high level of specifically peri-urban adaptations, including urban-oriented marketing efforts and adjustments to accommodate new urban neighbors. For peri-urban farms, diversification is often a viable strategy for farm survival, and is valued for its contribution to quality of life; and its value is likely to increase as the markets for locally-grown and

4 It seems not entirely a matter of happenstance that the historian, Geoffrey Blainey, who coined the term "the tyranny of distance", is Australian. 
regionally-differentiated agricultural products grow. Nevertheless, the stand-alone contribution of MFA opportunities at the urban fringe to big-picture economic competitiveness is probably rather modest.

- MFA may provide fertile opportunities for growth in high-amenity rural regions accessible to centers of agglomeration that offer opportunities for high-value work.

- MFA may generate growth in relatively remote highamenity regions, especially in-migration by consumers who are less disadvantaged by distance. Such consumers are often (but not always) retirees, which has obvious implications for the age structure of the local population and the kinds of urban services that that will experience growing demand. If pensions are received independent of current place of residence, local expenditures of retirees serve an economic function similar to remittances.

MFA and regional development objectives (2). Assume the goal is effective place-based economic development strategies. As noted above (footnote 1), the European concept of MFA policy includes some place-based economic development programs. However, there are limits to the optimism that should greet such policies. According to a fairly firm consensus among economists, supported by the smattering of empirical evidence that exists, place-based economic development policy has its own serious limits. ${ }^{5}$

The scope for MFA policy (as I have defined it here) in service of this objective is limited. Remoteness is nonresponsive to policy in the short-medium term, and the amenities that attract high-value workers and foot-loose consumers include many that are relatively non-responsive to policy - proximity to sea, lakes, mountains; pleasant climate; etc. Basically, amenity-oriented policies, including MFA, are likely to more effective in stimulating economic growth in the "silk purse" locations than in the "sow's ears". 6

A wild card: bio-energy and carbon sequestration may substantially increase farmland rents. As this is written, dramatic new policy commitments to green and renewable energy and sequestration of greenhouse gases are emerging, and seem likely to raise rural land rents, food prices, and transportation costs. Impacts of these developments on the regional and intra-regional dispersion of population and economic activity are, of course, speculative. We might expect labor employed in agriculture to increase somewhat, but not as much as land rents; and this increase would likely be concentrated in regions that were marginal for agriculture in the absence of these new energy and carbon related opportunities. We might expect any growth from this source in remote areas to be offset by increasing costs of remoteness as transportation costs increase (and the rise in transportation costs will be tempered by increases in fuel efficiency). The potentially negative impact of increasing land rents on economic development is likely to be rather restrained: urban and recreational uses of land seem able readily to outbid agriculture, and it is perhaps unlikely that agricultural rents will rise enough to reverse that situation. But, as I indicated, all of this is speculative.

I conclude by returning to a point made earlier. Marketfailure-correcting MFA policy will improve quality of life, well-being, and perhaps incomes in many if not all rural places regardless of location. And this accomplishment, should it be forthcoming, is not trivial - economic growth for all regions regardless of resources, amenities, and remoteness is simply not on the cards, and regions in decline face daunting problems maintaining essential services and quality of life (Kilkenny 2010). Growth is not everything regions unlikely to experience growth need to create satisfying futures.

\section{References}

Basile, R. (2008): Regional economic growth in Europe: a semiparametric spatial dependence approach. Papers in Regional Science 87(4): 527-544.

Blomquist, G., M. Berger and J. Hoehn. (1988): New Estimates of Quality of Life in Urban Areas. American Economic Review 78: 89-107.

Borota, T. and A. Kutan. (2008): Regional integration and economic growth: the case of the European Union, Journal of International Trade and Diplomacy 2(1): 93-113.

Boschma, R. and M. Fritsch. (2007): Creative class and regional growth in Europe. In P. Jacobowska, A. Kuklinski and P. Zuber (eds.) The Future of European Regions. Warzaw, Ministry of Regional Development.

Bureau, J-C. (2008): The sacred cow of rural development EuroChoices 7(1): 60.

Checherita, C., C. Nickel, and P. Rother. (2009): The Role of Fiscal Transfers for Economic Convergence in Europe. European Central Bank, Working Paper 1029.

Clark, J, D. Jackson-Smith, J. Sharp and D. Munroe. (2007): "The Geography of US Peri-Urban Agricultural Adaptation." Trans Atlantic Land Use Conference. September 24-26. Washington, DC.

Clark, J. (2009): The Repositioning of Farming in Newly Restructured, Consumptive Spaces: The Relational Geography of U.S. Peri-Urban Agriculture. PhD dissertation, Geography. Columbus, The Ohio State University.

Cochrane, N. and Wojan, T. (2008): Transatlantic similarities and contrasts in rural development policies. EuroChoices 7(1): 20-27.

Disdier, A-C., and K. Head. (2008): The puzzling persistence of the distance effect on bilateral trade. Review of Economics and Statistics 90: 37-48.

European Commission. (2006): Putting Rural Development to Work for Growth and Jobs. Directorate-General for Agriculture and Rural Development. http://ec.europa.eu/agriculture/lisbon/index_en.htm

\footnotetext{
5 This conclusion seems to be congenial to the World Bank (2009), which points to inter-territorial migration as the solution - people will develop even if many places don't.

6 "You can't make a silk purse out of a sow's ear" - attributed to Jonathon Swift (1667-1745).
} 
Florida R. (2002): The Rise of the Creative Class. Basic Books.

Friedman T. (2005): The World is Flat. Farrar, Straus and Giroux.

Fujita, M. and P. Krugman. (2003): The new economic geography: past, present and the future. Papers in Regional Science 83: 139-64.

Fujita, M. and J. Thisse. (2002): Economics of Agglomeration: Cities, Industrial Location and Regional Growth. Cambridge, England: Cambridge University Press.

Gabe, T., K. Colby, and K. Bell. (2007): The effects of workforce creativity on earnings in US counties. Agricultural and Resource Economics Review 36: 71-83.

Gylfason, T. (2000): Resources, Agriculture, and Economic Growth in Economies in Transition. CESifo Working Paper 313. Munich.

Hoyman, M. and Faricy, C. (2009): It takes a village: a test of the creative class, social capital, and human capital theories. Urban Affairs Review 2009; 44; 311-333.

Irwin, E., A. Randall, and Y. Chen. (2008): Exploring the prospects for amenity-driven growth in rural areas. In J. Wu, P. W. Barkley and B. A. Weber (eds.), Frontiers in Resource and Rural Economics: Human-Nature and Rural-Urban Interdependencies. Washington DC: Resources for the Future, Inc., 82-93.

Kilkenny, M. (2010): Urban/regional economics and rural development. Journal of Regional Science 50: (in press).

Krugman, P. (1993): First nature, second nature, and metropolitan location. Journal of Regional Science 33: 129-144.

Krugman, P. (1991): Increasing returns and economic geography. Journal of Political Economy 99: 483-499.

Leamer, E. (2007): A flat world, a level playing field, a small world after all, or none of the above? A review of Thomas L. Friedman's The World is Flat. Journal of Economic Literature 45: 83-126.

McGranahan, D. and Wojan, T. (2007): Recasting the creative class to examine growth processes in rural and urban counties. Regional Studies 41: 197-216.

Nilsson, F., K.P Hasund, I-N Gren, and Y. Surrey. (2008): Multifunctional agriculture - what does the literature tell us? International Review of Environmental and Resource Economics 2: 281-319.
Partridge, M. (2008): "Amenity-driven growth: recent trends and future directions", presented at Freshwater and the Great Lakes Economics Future Workshop, Federal Reserve Bank of Chicago, Detroit branch, Detroit, MI, November 10.

http://aede.osu.edu/programs/Swank/Amenity_Growth_FedrResC hicago_2008.pdf

Partridge, M., D. Rickman, K. Ali and M. Olfert. (2008): Lost in space: population dynamics in the American hinterlands and small cities. Journal of Economic Geography 8(6): 727-757.

Partridge, M., D. Rickman, K. Ali, and M. Olfert. (2009): Spatial Growth Dynamics in Wages and Housing Costs: The Role of Distances from Urban Production Externalities and Consumer Amenities. http://aede.osu.edu/programs/Swank/.

Randall, A. (2007): A consistent valuation and pricing framework for non-commodity outputs: progress and prospects, Journal of Agriculture, Ecosystems, and Environment 120: 21-30.

Randall, A. 2003: Pricing the outputs of multifunctional agriculture, Taiwanese Agricultural Economics Review 9(1): 1-29.

32. Randall, A. (2002): Valuing the outputs of multifunctional agriculture, European Review of Agricultural Economics 29: 289-307.

Rappaport, J. and J. Sachs. (2003): The United States as a coastal nation. Journal of Economic Growth, 8: 5-46.

Romstad, E. (2004): Policies for promoting public Goods in agriculture. In Brouwer, F. (ed.), Sustaining Agriculture and the Rural Environment: Governance, Policy and Multifunctionality, Edward Elgar, Cheltenham, UK. 56-77.

Sohn, J., T. Kim, and G. Hewings. (2002): Information technology impacts on urban spatial structure in the Chicago region. Geographical Analysis 34: 313-329.

Winter, M. (2008): We need rural development. EuroChoices 7(1): 61.

World Bank. (2009): World Development Report 2009: Reshaping Economic Geography, Washington DC. 